\title{
Interfacing Small Wind Systems to Rural Power Distribution Systems
}

\author{
LEO H. SODERHOLM, MEMBER, IEEE
}

\begin{abstract}
The majority of current wind energy conversion systems (WECS) are designed for interconnection to the electric utility grid. Although this type of application performs satisfactorily in most instances when only a few WECS are connected to the electrical distribution system, several problems seem to be of concern as WECS use becomes widespread. For interconnected WECS a number of concepts related to WECS performance and economics must be considered so that safe operation, maximum utilization of WECS energy, and avoidance of interference to normal utility operation may be achieved. Methods and factors that must be considered for interfacing wind turbines to electric utilities are presented in relation to application and performance.
\end{abstract}

\section{INTRODUCTION}

W ITH THE ADVENT of regulations for the implementation of Section 210 of the Public Utilities Regulatory Policies Act (PURPA) of 1978, a great deal of interest has developed in power production in parallel with electrical utility systems. Although a number of renewable energy sources such as wind, small hydroelectric systems, or solar may be used for cogeneration of electrical energy by individuals, wind energy is one of the most widely available resources that is economically feasible at present.

Major provisions relating to Section 210 of PURPA that encourage power production through interfacing with a utility grid are as follows.

1) Utilities are required to furnish electrical power to qualifying facilities on a nondiscriminatory rate basis that is just and reasonable.

2) Utilities must purchase power from such facilities at a rate reflecting the cost that the purchasing utility can avoid as a result of obtaining energy from these sources.

3) Electric utilities must make available to cogenerators and small power producers data concerning present and future costs of energy on their system so that the economics of cogeneration may be evaluated.

At present, a great deal of controversy exists regarding the PURPA rules, particularly in regard to an assignment of value for avoided costs and the constitutionality of the regulations. Interconnection to a utility grid, however, is a method of using wind energy that many wind systems currently employ, and the effects and issues of such interconnection need to be carefully considered.

Paper GID 83, approved by the Rural Electric Power Committee of the IEEE Industry Applications Society for presentation at the 1983 Rural Electric Power Conference, Des Moines, IA, April 24-26. Manuscript released for publication June 24, 1983. This work was supported in part by the Agricultural Research Service, U.S. Department of Agriculture, in cooperation with the Iowa Agriculture and Home Economics Experiment Station, Ames, Iowa, Project No. 2125.

The author is with the Agricultural Research Services, U.S. Department of Agriculture, Iowa State University, Ames, IA 50011.
Most currently designed wind energy conversion systems (WECS) are intended for interconnection to the utility grid for supplying conventional ac power. Although this type of application performs satisfactorily in most cases in which the number of WECS on a given distribution system is small, a number of problems with interconnected WECS seem to be a cause for concern as the number of WECS increases.

Utilities have a problem with any type of load or cogeneration source that affects their quality of service or planning and operation of the system. The potential for an increased number of WECS on distribution systems in rural areas and the variability of their output make consideration of approaches that minimize interactions highly desirable. There is growing recognition that, although large numbers of WECS have been successfully interfaced to utility systems, potential problems continue to exist.

\section{INTERCONNECTION METHODS}

Three general methods are being used for supplying normal $120 / 240-480-\mathrm{V}$ single- or three-phase ac requirements from WECS through interconnection with the utility grid. These include the use of induction generators, synchronous alternators, or synchronous inverters connected to the utility-supplied electrical service. Energy from such interconnected WECS may be used for purposes such as heating, lighting, irrigation, or general electrical power for farm or residential applications. Although all three systems used for interconnection allow the use of wind energy in a form compatible with utility power, a wind system using these methods of generation cannot generally supply energy if power is not available from the utility system. Each method of interconnection presents both advantages and problems.

\section{A. Induction Generators}

An induction generator is essentially an ac motor driven at a speed above its normal synchronous speed. The induction generator has a number of advantages: low cost, simplicity, and-because of its relatively constant-speed characteristics-accommodation of a wide wind-speed range without generator overload.

The induction generator, however, is not without disadvantages. Some type of automatic disconnecting means must be provided if the rotational speed is below synchronous speed, or the generator will become a motor. This problem may be overcome by several methods such as a wind-speed or a rotational-speed monitor to make the connection only if the proper conditions are met. The possibility does exist that the unit may become self-excited under certain conditions; therefore, it is necessary to ensure that, in case of 
utility power failure, the unit will be disconnected from the line. Because this generally will unload the generator, some method of preventing a wind-turbine over-speed condition also becomes essential. At critical wind speeds near cut-in, excessive cycling on and off the line may occur that can produce undesirable flicker and transients. The excitation required for an induction generator also contributes to a lagging power factor on the distribution system; the coefficient of performance of the WECS drops as wind speeds exceed an upper level, and, because the induction generator must be up to a specific speed to generate, it cannot capture energy below a cut-in wind speed that may be somewhat greater than for other systems.

\section{B. Synchronous Inverters}

A synchronous inverter generally is a solid-state device that can take a variable dc voltage input and apply this energy to the ac line. Usually, the $\mathrm{dc}$ is produced by a winddriven alternator and rectified for application to the inverter. An inductor may be required to interface the rectified dc output with the converter and may add substantially to the cost.

Synchronous inverters can operate without energy storage by using the utility system for excess energy as with induction generators, but synchronous inverters also have the capability of operating with stored dc energy from batteries if the utility line voltage is present for synchronization. For some applications, it also may be possible to use the alternator output on a "stand-alone" basis if line power is not available for such purposes as resistance heating, for which variable voltage and frequency are satisfactory.

The primary disadvantages of a synchronous inverter as compared with an induction generator are a higher system cost, the introduction of harmonics that may cause electrical interference, a greater complexity that may increase service problems, a susceptibility to problems of low line voltage, and a possible reduction of efficiency at power levels that are low in relation to rated converter power capability.

A guide for the harmonic control and reactive compensation of static power converters has been prepared by the IEEE Static Power Converter Committee to establish design practices for static converters. This document recognizes the problems that may occur with static power converters and outlines procedures that should be followed to minimize undesirable interactions.

\section{Synchronous Alternators}

Synchronous alternators are a well-known method of electrical generation and possess a number of advantages such as the possibility of voltage and load control through variation in field current. For interconnection and synchronization to a utility grid, however, their speed must be held constant. This may require speed regulation of the wind system and a method of synchronization that adds to the system cost and complexity. In general, this method of cogeneration has proved less satisfactory than induction generators and synchronous converters because of the difficulty of maintaining a constant generator speed with the variability of WECS speed.

\section{PARALLEL GENERATION CONCERNS}

A number of concerns are related to the interfacing of cogenerated power with a utility. In general, most of these relate to the problems of the utility in meeting their obligation of supplying electrical energy that meets their service standards to all customers and that avoids interference to the system operation.

\section{A. Safety}

The safety of personnel working on the utility lines is one of the foremost considerations for any method of interconnection. Under certain circumstances, self-excitation of WECS may occur when the utility feeder is deenergized. Although automatic protection such as voltage and frequency monitors can be obtained for preventing such problems, the economics and reliability of such protection usually favor a simple lockout switch.

In general, induction generators and synchronous inverters will not back-feed into the distribution system because they become inoperative with no power on the utility service. In addition, most designs have a disconnect device (usually a line-power operated relay) that provides a disconnect from the utility service if power is not present. In spite of the safety aspects, of these considerations, true safety and many utility regulations require that a positive lockable disconnect switch shall be installed between the WECS and the utility service as shown in Fig. 1 so that a positive disconnection can be assured. This switch must be accessible to utility personnel at all times so that, in case of power outage or malfunction of the wind system that could cause problems to the utility or other customers, the WECS can be removed from the distribution system.

\section{B. Power System Considerations}

The WECS interconnection to a utility distribution system introduces a number of additional problems to electrical utility system operation that need careful consideration by both the cogenerator and the utility. These issues have been discussed by several authors (Curtice et al. [1] , Soderholm [4], Endahl [2], and Zastrow [5]).

The major concerns of electrical utilities related to cogeneration, other than safety, are the possible effects on the system operation. If a number of WECS are interfaced on a particular distribution system, problems may arise in maintaining the quality of service.

If one or more sizable wind system is installed and operated on a single phase of a three-phase distribution system, voltage unbalance may be created on the three-phase system that can have undesirable effects on three-phase motor operation. When line voltages applied to a polyphase induction motor are not exactly the same, unbalanced currents will flow in the stator winding. Small amounts of unbalance produce substantial increases in current that may overheat the motor. In the phase with the highest current, the percentage increase in temperature rise will be approximately twice the square 


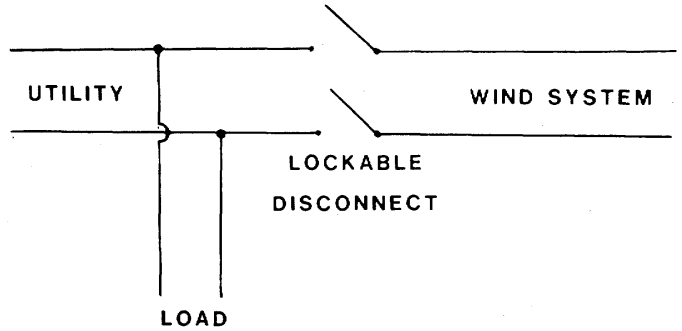

Fig. 1. Lockable disconnect switch for safety so that positive isolation of WECS can be assured by utility personnel.

of the percentage voltage unbalance [3]. An approximate rise in temperature of 25 percent may be caused by only a 3.5-percent voltage unbalance. Wind system interconnection effects also may occur as perturbations in service voltage, frequency, flicker, and harmonics that possibly may damage either utility or customer equipment.

The inrush of current to a large induction generator during startup can cause a dip in the voltage on a distribution feeder. This condition, referred to as flicker, causes lights to dim noticeably and motors to slow down momentarily. Certain electronic equipment can be interrupted or damaged.

When variable winds are encountered at approximately the power level that will just bring the WECS up to the synchronous speed, numerous connections and disconnects may occur and produce unacceptable numbers of flicker occurrences. Most utilities have regulations concerning flicker, and WECS will be expected to conform.

The operation of dispersed WECS will most likely reduce the normal voltage drop along a distribution feeder. This effect on automatic utility voltage-control equipment is not readily apparent and will have to be evaluated in each specific case where problems of voltage control are expected or encountered. A momentary disruption of power such as occurs when line faults are encountered and recloser action initiates several rapid deenergizings of the line may damage both induction generators and line-commutated synchronous inverters.

If the utility voltage is lost and the residual voltage on the wind generator's terminals decays rapidly, the wind system may be isolated by an instantaneous undervoltage relay or an overspeed protection relay. However, if the generator selfexcites, the voltage and/or frequency output of the machine may drift away from the utility voltage and frequency. If this occurs at the same time that the utility system recloses, an instantaneous torque will be produced in the wind-turbine rotor that is proportional to the phase difference between the machine's output parameters and the utility current, and damage to the WECS may occur.

In addition, the reactive power requirements on the system may be increased by the excitation requirements of WECS. Even though power factor correction is possible with both induction generators and line-commutated inverters, such correction may result in additional problems. With induction generators, the possibility of self-excitation increases, and with synchronous inverters, the required capacitance is not constant because the reactive power varies with load, as shown in Fig. 2.

The distribution problems of system protection, coordina-

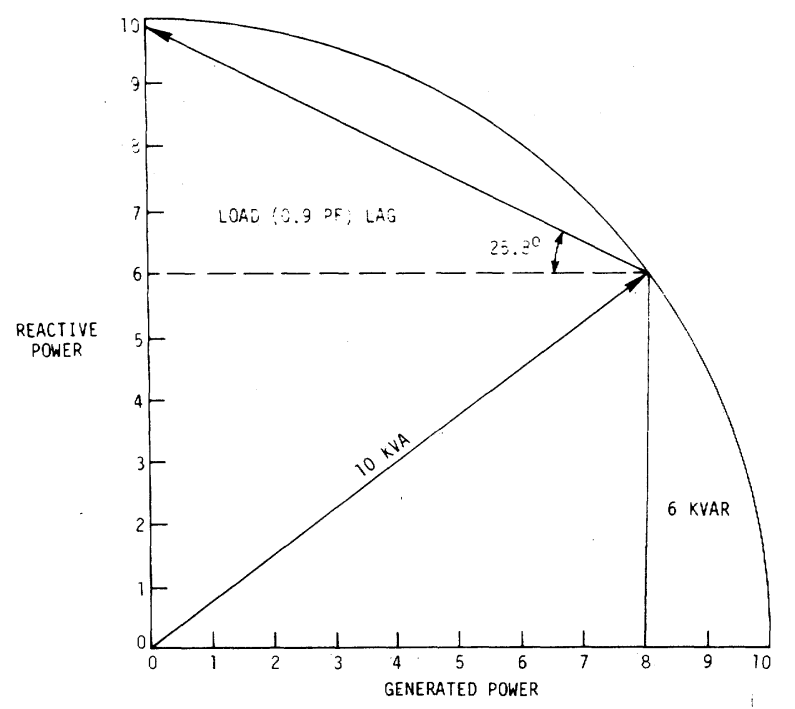

Fig. 2. Line-commutated synchronous $10-\mathrm{kW}$ inverter, reactive power versus real power for $8 \mathrm{~kW}$ of generated power.

tion, line or generator tripping, load modeling, and stability analysis also may be affected. If a system fault occurs as shown in Fig. 3, the WECS may contribute to that fault and possibly cause the system protection to open, thus shutting down a portion of the distribution system.

The interconnection of cogeneration facilities also introduces problems in determining rate structures and costs of service. Additional metering is required to determine the amount of power the cogenerator feeds back into the utility grid unless the billing meter is allowed to run backward. This in effect is reimbursement at retail rate and does not necessarily reflect the "avoided cost," particularly if the power is fed back at a time when the utility has excess capacity. The minimum metering requirement for determining both purchased and fed-back power is shown in Fig. 4. Although this separates the two basic classes of power, it gives no indication of the reactive power requirements of the WECS. The metering shown in Fig. 5 indicates a more elaborate determination of kilowatt hours provided to the service, the fed-back power, and the reactive power supplied to the WECS. Numerous other metering schemes can be employed, and the choice will, of necessity, be determined on the cost of the metering, the complexity of ob: taining and using readings, and the economic benefit of the determination of each power component.

\section{Utility Interface Requirements}

Because of potential problems associated with interconnection, utilities may have very specific requirements regarding the electrical interface methods and equipment. In addition, liability insurance carried by the cogenerator may be required to provide protection in case of damage to the utility or customer equipment. Some utilities are requiring general liability insurance to cover the bodily injury and property damage responsibilities of the cogenerator as well as a mutual "hold harmless" clause. Under the clause, the utility and the cogenerator will hold the other harmless for injuries or damages arising from their respective operations. 


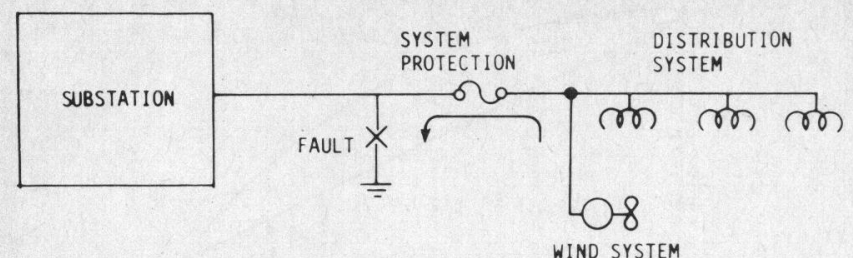

Fig. 3. Possible fault contribution by wind system that may open system protection and isolate section of distribution system.

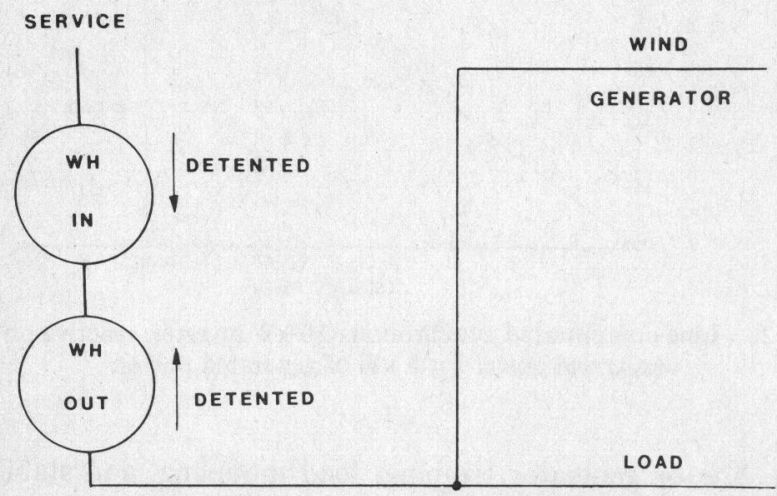

Fig. 4. Metering to determine both purchased and fed-back power.

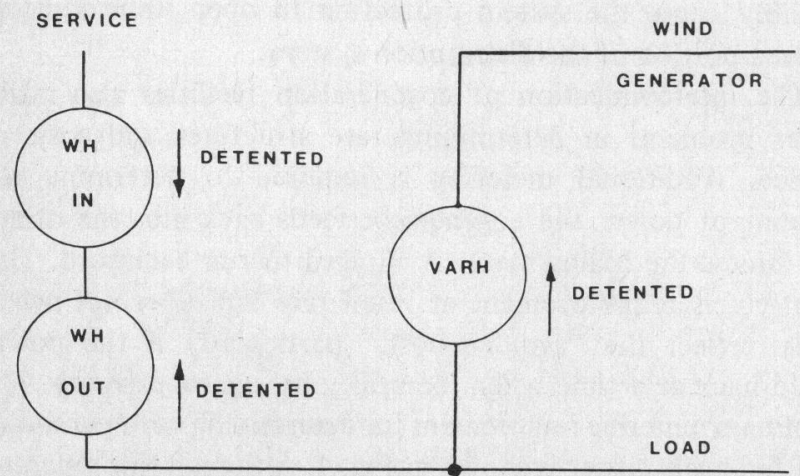

Fig. 5. Metering to determine kilowatt hours provided to service, power production fed back to utility, and reactive power supplied to WECS.

\section{CONCLUSION}

Most WECS currently being manufactured are designed for interconnection to a utility grid. Many of the problems of safety, liability, metering, and undesirable interaction with the utility system may become more of a problem to utilities as the number of WECS installations increase.

Even though, on the surface, interconnection seems to offer a lower cost and simplicity of a WECS system, the institutional, technical, and economic problems associated with the interconnection of WECS to a utility grid must be carefully considered in the application of such systems if undesirable interactions with the utility service are to be avoided and proper evaluation of the value of the cogenerated power is to be made.

Continuing research on the interfacing problems of cogenerators to utility grids is desirable if problems are to be avoided and WECS are to make their full contribution to load leveling and the reduction of use of nonrenewable energy resources.

\section{REFERENCES}

[1] D. Curtice, J. Patton, and N. Sechan, "Study of dispersed small wind systems interconnected with a utility distribution system," U.S. Dep. Energy, Contract DE-AC04-76DP03533, National Tech. Inform. Service RFP-3093/94445/3533/80/7 VC-60, 1980.

[2] L. Endahl, "REC experiences and concerns with interconnection of small wind energy systems," in Proc. 5th Biennial Conf. Wind Energy Conversion Systems, 1981, pp. 329-335, (National Tech. Inform. Service-SERI/CP-635-1212).

[3] Motors and Generators Standards, NEMA Standard MG1-1969, sec. MG1-14.33.

[4] L. Soderholm, "Interfacing wind systems to the utility grid," Amer. Soc. Agric. Eng. Paper 80-3042, 1980.

[5] O. Zastrow, "Study of technical problems associated with interconnection of wind generators on rural electric cooperative distribution lines," Nat. Rural Elec. Coop. Assoc., Res. Project Rep. 80-2, 1981.

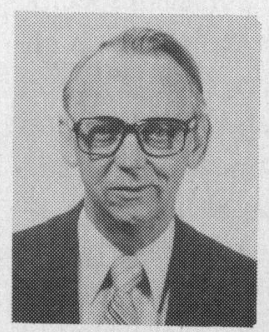

Leo H. Soderholm (S'49-A'50-M'55) received the B.S. and M.S. degrees in electrical engineering from The University of Nebraska, Lincoln, and the Ph.D. degree in agricultural engineering from Iowa State University, Ames, in 1949, 1953, and 1971, respectively.

From 1959 to 1962 he was a Manager with RCA's Nuclear Instrumentation Services, Los Angeles, CA. From 1962 to 1966 he was a Design Engineer with Varian-Aerograph, Walnut Creek, CA. Since 1966 he has been a Research Leader with the Agricultural Engineering Research Group of the U.S. Department of Agriculture's Agricultural Research Service, stationed at Iowa State University, Ames. His research is concerned with wind energy and the application of electrical power in agricultural production. 